\title{
The association between perceived patient-centered care and symptoms experienced by patients undergoing anti-cancer treatment
}

\author{
Inna Tsvitman ${ }^{1,2} \cdot$ Orit Cohen Castel ${ }^{2,3,4} \cdot$ Efrat Dagan $^{2}$ (D \\ Received: 27 September 2020 / Accepted: 5 April 2021 / Published online: 14 April 2021 \\ (C) The Author(s), under exclusive licence to Springer-Verlag GmbH Germany, part of Springer Nature 2021
}

\begin{abstract}
Purpose Cancer patients undergoing active anti-cancer treatment experience multiple symptoms concurrently. Over the years, studies to improve patients' physical and psychological discomfort by focusing on patients' needs and preferences have reported promising outcomes. This study aims to explore perceived patient-centered care and its association to symptoms experienced by cancer patients undergoing active anti-cancer treatment.

Methods A cross-sectional study was conducted at an outpatient cancer center between August 2018 and July 2019 among adult cancer patients receiving chemotherapy and biological therapy. Participants were asked by their oncology nurse to complete a self-administered questionnaire which included the three subscales (physical, psychological, and global distress) of the Memorial Symptoms Assessment Scale as well as the perceived patient-centered care questionnaire. To examine the association between participants' perceived patient-centered care and each of the symptoms scale scores, three hierarchical (block-wise) linear regression models were performed.

Results Of the 125 participants, 57 (45.6\%) were diagnosed with breast cancer and were treated with chemotherapy either alone $(n=62,49.6 \%)$, with radiotherapy $(n=4,3.2 \%)$, or with biological therapy $(n=45,36.0 \%)$. Hierarchical regression models found that perceived patient-centered care contributed to $11.3 \%, \beta=-.351(p<0.001) ; 8.9 \%, \beta=-.311(p<0.001)$; and $10.3 \%$ $\beta=-.336(p<0.001)$ of the variance of the global distress index, physical symptoms, and psychological symptoms, respectively. Conclusions This study shows the importance of perceived patient-centered care in alleviating physical and psychological symptoms and overall distress in cancer patients undergoing active anti-cancer therapy. Our findings call for oncology teams to adopt and implement patient-centered care as part of their routine work.
\end{abstract}

Keywords Cancer patients $\cdot$ Anti-cancer treatment $\cdot$ Symptom experience $\cdot$ Perceived patient-centered care

\section{Introduction}

Patient-centered care (PCC) is a multifaceted approach concerning the interactions between patients, healthcare

Efrat Dagan

edagan@univ.haifa.ac.il

Cancer Center, Emek Medical Center, Afula, Israel

2 The Cheryl Spencer Department of Nursing, Faculty of Social Welfare and Health Sciences, University of Haifa, 199 Aba Khoushy Avenue, Mount Carmel, 3498838 Haifa, Israel

3 The Ruth and Bruce Rappaport Faculty of Medicine, Technion Israel Institute of Technology, Haifa, Israel

4 The Department of Family Medicine, Meuhedet Health Services, Northern District, Israel providers, and the healthcare environment. PCC aims to increase the quality of care given to patients by alleviating their suffering, reducing disparities in healthcare services, minimizing unnecessary use of health services, and in turn reducing mortality rates [1-4]. PCC is consequently defined as the provision of care that respects the individual patient's needs, values, and perspective and is customized accordingly [5]. The concept of PCC stems from the American humanist Carl R. Rogers' (1945) theory on client-centered therapy [6]. It proposes six dimensions which comprise exploring the disease or illness experience, understanding the whole person, finding common ground, incorporating prevention and health promotion, enhancing the patienthealthcare provider relationship, and being realistic [7]. The PCC approach has received new prominence with its inclusion by the Institute of Medicine as one of the six aims of quality of care. The delivery of PCC entails access to care, patient 
engagement in care, information systems, care coordination, and integrated and comprehensive team care $[1,5]$.

Although PCC is increasingly acknowledged as a core value in the treatment of chronic conditions including cancer $[8$, 9], studies have shown that cancer patients from marginalized and minority groups, lower socioeconomic status, older age, lower health literacy, and profiency and without health insurance often receive lower levels of PCC [2, 10-12]. Still, having an informal caregiver was found to be associated with better quality of cancer care $[13,14]$. On the other hand, lower levels of PCC have also been perceived by cancer patients with higher education and higher income and by nonHispanic white patients $[15,16]$.

Studies have also shown that PCC is not well implemented throughout the cancer care trajectory, including for patients undergoing active anti-cancer treatment [4, 17-22]. During the active treatment phase, patients frequently report more than eight concurrent symptoms which impact their daily functioning and overall quality of life and well-being [23-25]. The most prevalent of these symptoms include fatigue, anxiety and distress, pain, sleep disturbances, decreased appetite, cachexia, and sexual problems [23, 24, 26, 27]. These symptoms have been found to be associated with many sociodemographic and clinical factors. For example, in a study examining a large cohort of breast cancer patients 1 year after diagnosis, greater comorbidity, a more advanced stage at diagnosis, a younger age, urban residence, a lower income, and chemotherapy were all associated with a greater symptom burden [28]. Similarly, among colorectal cancer patients, a younger age at diagnosis was associated with a higher symptom burden; males were more concerned about sexual dysfunction than females; and symptoms of depression and anxiety were more prevalent in women, patients with comorbidities, and those with a shorter time since diagnosis $[29,30]$. Among prostate cancer patients, sexual problems predicted higher levels of distress, fatigue, and insomnia [26, 27]. Taking together these studies' findings, integrated analyses have shown that symptoms can be grouped into several types of clusters, including somatic, psychological, respiratory, and nutrition or gastrointestinal, and that specific demographic and clinical factors predict a particular type of symptom cluster [25, 31]. For example, low income and radiation therapy or chemotherapy have predicted a higher somatic symptom burden. Younger age, being female, a low income, and surgical treatment have predicted more psychological symptomatology, and older age and surgical treatment have predicted a higher nutritional burden. Moreover, patients with a higher cluster symptom burden have reported higher distress [31]. Yet, empirical studies that have examined the relationship between different aspects of PCC and specific health outcomes are relatively limited [4].

Overall, in the oncology contex, the critical role of PCC and its association with better clinical outcomes is well acknowledged [1, 4, 32, 33]. However, most of these studies have looked at cancer patients' needs and preferences in the context of advanced disease stages and end of life [3, 18, 34-36]. Others have focused on interventions based on PCC principles and their associations with patient satisfaction and quality of life [36]. Additionaly, several studies have described the effectiveness of diverse medical and nursing interventions to alleviate symptom discomfort in cancer patients; yet, these studies were conducted at the end of life [36]. The current literature, however, lacks studies that have examined the association between perceived PCC and the symptoms patients experience, while undergoing active anti-cancer treatment, beyond their sociodemographic and clinical characteristics [36]. The current study, therefore, aims to fill this gap by exploring perceived PCC and its association to symptoms experienced by cancer patients undergoing active anti-cancer treatment.

\section{Methods}

\section{Study design and procedure}

A cross-sectional study was conducted at the outpatient cancer center of the Emek Medical Center between August 2018 and July 2019. Participants were recruited after receiving an explanation about the study aims and procedure, and providing their signed informed consent. Patients at the end of the second cycle of treatment of either chemotherapy or biological therapy as a single therapy or a combined therapy of chemotherapy with either radiation or biological therapy were recruited. This point of recruitment was chosen to enable patients to become familiar with the healthcare team and to evaluate their perceived PCC in association with symptoms they experienced while undergoing such active anti-cancer treatment. Eligible patients were requested by their oncology nurse to complete a self-administered validated questionnaire as well as sociodemographic information. Completing the questionnaire took about $20 \mathrm{~min}$ on average. Clinical data were collected from the patients' medical records.

The study was approved by the Emek Medical Center's Helsinki committee (\#EMC-18-0021) and the University of Haifa's ethical committee (\#149/18).

\section{Participants}

Participants were included if they were cancer patients diagnosed with a solid tumor, were over 18 years old, and were Hebrew speakers. Patients were excluded if they had cognitive deficits, were pregnant, were diagnosed with hematological malignancies, were under 18 years of age, or were nonHebrew speakers. For a medium effect size of 0.15 at alpha $=0.05$, a sample size of 125 participants were needed to achieve a statistical power of 0.80 [37]. 


\section{Study questionnaire}

The study questionnaire included the following instruments:

Dependent variables: The Memorial Symptoms Assessment Scale (MSAS-Heb). This was originally developed and validated by Portnoy et al. [38] to study the physical and psychological symptoms of cancer patients. We used the Hebrew version which was translated and validated by Pud [39]. The MSAS-Heb consists of 26 symptoms where patients were asked to rate their frequency, severity, and level of distress on five point Likert scales ranging from 0 (did not have) to 4 (almost constantly/very severe/very much). The total score for each symptom is calculated by averaging the frequency, severity, and distress scores of each symptom. The questionnaire is divided into three scales that measure physical symptoms, psychological symptoms, and a global distress index (GDI). The physical scale includes 12 distress items: lack of energy, pain, lack of appetite, feeling drowsy, constipation, dry mouth, nausea, vomiting, change in taste, weight loss, feeling bloated, and dizziness. The psychological scale consists of six distress items: worrying, feeling sad, feeling nervous, difficulty sleeping, feeling irritable, and difficulty concentrating. The GDI includes four frequency items: feeling sad, worrying, feeling irritable, and feeling nervous; and six distress items: lack of energy, pain, lack of appetite, feeling drowsy, constipation, and dry mouth. According to Pud [2], Cronbach's alpha internal consistency was 0.90 for the all 32 items, 0.80 for the physical subscale, 0.78 on the psychological subscale, and 0.83 on the GDI scale. Independent variable: Perceived Patient-Centered Care questionnaire (PCC) [40]. This was developed to assess cancer patients' perceptions of patient-provider communication and design measures of patient-centered communication. The PCC consists of 36 items divided into six subscales: Exchanging Information, Fostering Healing Relationships, Making Decisions, Responding to Emotions, Enabling Patient Self-Management, and Managing Uncertainty. We used the short form of the instrument that includes one question from each subscale. Responses range from 1 (not at all) to 5 (very much) on a five-point Likert scale. The PCC total score is calculated by averaging the total scores of the six items. The questionnaire was validated by Reeve et al. on 501 colorectal cancer patients with a Cronbach alpha internal consistency of 0.92 . The items were translated from English to Hebrew and back translated as customary [40].

Covariates: The questionnaire included information on the study participants' socio-demographic characteristics, such as gender, age, level of education, religion, marital status, and employment status.
Additionally, clinical information, such as type of cancer, age at diagnosis, and type of treatment, were collected from patients' medical files.

\section{Statistical analysis}

Descriptive statistics (frequency, distribution, means, and standard deviation) were used to describe the participants' socio-demographics and clinical characteristics, as well as the MSAS-Heb and perceived PCC scores. Differences between the PCC items mean score were analyzed using oneway analysis of variance (ANOVA). Associations between dependent variables (MSAS-Heb) and independent variables (perceived PCC) or potential confounders (sociodemographic and clinical characteristics) were assessed using $t$ tests or Pearson correlations. In order to study the association between the participants' perceived PCC and each scale of the MSAS-Heb scores (either physical, psychological, or GDI) beyond socio-demographic and/or clinical variables, we performed hierarchical (block-wise) linear regression model for each scale of the MSAS-Heb questionnaire. In each model, the first step included the socio-demographic and clinical variables, and in the second step, the perceived PCC scores were added. Socio-demographic and clinical variables were included in the model if in the bivariate analyses, an alpha level of 0.05 or a Pearson correlation of $\geq 0.3$ was reached for their association with either perceived PCC or each of the MSASHeb subscale scores. Associations between potential predictors in the model were examined in bivariate analyses to avoid co-linearity. All analyses were performed using the SPSS version 23.0 statistical program (SPSS Inc., Chicago, IL).

\section{Results}

Table 1 describes the socio-demographic and clinical characteristics, as well as the mean scores and standard deviations of the perceived PCC and symptom scales (MSAS-Heb) of the cancer patients included in the study. Of the 125 study participants, $45.6 \%$ were breast cancer patients $(n=57)$, almost half were treated for advanced disease $(57,45.6 \%)$, and the majority received chemotherapy either alone $(62,49.6 \%)$ or in combination with biological therapy $(45,36 \%)$ or radiation therapy $(4,3.2 \%)$. The lowest mean score of the perceived PCC subscales was obtained for Responding to Emotion (mean = 3.71; $\left.\mathrm{SD}=1.25 ; F_{(5)}=10.94, p<0.001\right)$. Cronbach alpha of the current sample for the perceived PCC questionnaire was 0.91 .

Higher perceived PCC scores were found among married patients compared to all other family statuses (married $=4.32$ \pm 0.68 vs. divorce, single or widow $=3.85 \pm 0.94 ; p<0.05$ ); among non-Jewish patients compared to Jewish patients (4.46 
Table 1 Socio-demographic and clinical characteristics of the 125 cancer patients

Socio-demographic characteristics
Age (years)
Gender
Family status
Accompanied for treatments
Place of birth
Religion
Education
Perceived economic status
Clinical characteristics
Type of cancer

Type of treatment

Treatment protocol

Perceived patient-centered care

Symptom scales

\begin{tabular}{|c|c|}
\hline & Mean (SD) \\
\hline & $59.3(14)$ \\
\hline & $n(\%)$ \\
\hline Women & $80(64.0)$ \\
\hline Married & $91(72.8)$ \\
\hline With a companion & $108(86.4)$ \\
\hline Israel & $67(53.6)$ \\
\hline Jewish (vs. Muslim or Christian) & $99(79.2)$ \\
\hline Above high school (vs. high school or below) & $62(49.6)$ \\
\hline Good or very good (vs. not good or bad) & $102(81.6)$ \\
\hline & $n(\%)$ \\
\hline Breast & $57(45.6)$ \\
\hline Colon-rectal & $33(26.4)$ \\
\hline Lung & $19(15.2)$ \\
\hline Pancreas & $5(4.0)$ \\
\hline Gastric & $4(3.2)$ \\
\hline Prostate & $2(1.6)$ \\
\hline Testes & $2(1.6)$ \\
\hline Melanoma & $1(0.8)$ \\
\hline Bladder & $1(0.8)$ \\
\hline Sarcoma & $1(0.8)$ \\
\hline Chemotherapy & $62(49.6)$ \\
\hline Biological therapy & $14(11.2)$ \\
\hline Chemo- and radiation therapy & $4(3.2)$ \\
\hline Chemo- and biological therapy & $45(36.0)$ \\
\hline Neo-adjuvant & $22(17.6)$ \\
\hline Post-operative & $46(36.8)$ \\
\hline For advanced disease & $57(45.6)$ \\
\hline & Mean (SD) \\
\hline Exchanging information & $4.50(0.69)$ \\
\hline Fostering healing relationships & $4.42(0.80)$ \\
\hline Making decisions & $4.29(0.86)$ \\
\hline Enabling patient self-management & $4.22(0.94)$ \\
\hline Managing uncertainty & $4.07(1.05)$ \\
\hline Responding to emotions & $3.71(1.25)$ \\
\hline & Mean (SD) \\
\hline Physical symptoms & $1.05(0.94)$ \\
\hline Psychological symptoms & $1.42(1.28)$ \\
\hline Global distress index (GDI) & $1.33(0.88)$ \\
\hline
\end{tabular}

\pm 0.79 vs. $4.12 \pm 0.72$, respectively; $p<0.05$ ); and accompanied (have a companion during treatment) compared to unaccompanied patients $(4.35 \pm 0.65$ vs. $3.96 \pm 0.90$, respectively; $p<0.05)$.

Participants' ratings of their symptoms' frequency, severity, and distress and the MSAS-Heb subscale scores are detailed in Table 2. Cronbach alpha of the current sample for the MSAS-Heb questionnaire was 0.849 for the physical symptoms scale, 0.879 for the psychological symptoms scale, and 0.867 for the GDI scale. All three MSAS-Heb scales were found to have high significant correlations with each other $(r$ $=.715, p<0.001$ for the correlation between the physical symptoms scale and the psychological symptoms scale; $r=$ $.891, p<0.001$ for the correlation between the physical symptoms scale and the GDI; and $r=.923, p<0.001$ for the correlation between the psychological symptoms scale and the GDI).

A perceived low economic status compared to a perceived good economic status was associated with higher psychological symptoms $(2.04 \pm 1.22$ vs. $1.28 \pm 0.91$, respectively; $p<$ 
Table 2 Symptom frequency, severity, and distress scores

\begin{tabular}{lllll}
\hline Type of symptom & $\begin{array}{l}\text { Prevalence } \\
n(\%)\end{array}$ & $\begin{array}{l}\text { Frequency score } \\
\text { Mean (SD) }\end{array}$ & Severity score & Distress score \\
\hline Lack of energy & $102(81.6)$ & $2.18(1.31)^{\mathrm{b}}$ & $1.87(1.14)^{\mathrm{b}}$ & $1.72(1.24)^{\mathrm{a}, \mathrm{b}}$ \\
Worrying & $88(70.4)$ & $1.73(1.41)^{\mathrm{a}, \mathrm{c}}$ & $1.65(1.35)^{\mathrm{c}}$ & $1.50(1.39)^{\mathrm{c}}$ \\
Pain & $86(68.8)$ & $1.70(1.42)^{\mathrm{b}}$ & $1.49(1.27)^{\mathrm{b}}$ & $1.38(1.33)^{\mathrm{a}, \mathrm{b}}$ \\
Feeling drowsy & $86(68.8)$ & $1.71(1.40)^{\mathrm{b}}$ & $1.40(1.22)^{\mathrm{b}}$ & $1.26(1.30)^{\mathrm{a}, \mathrm{b}}$ \\
Difficulty sleeping & $83(66.4)$ & $1.81(1.50)^{\mathrm{c}}$ & $1.64(1.39)^{\mathrm{c}}$ & $1.44(1.35)^{\mathrm{c}}$ \\
Feeling irritable & $82(65.6)$ & $1.65(1.43)^{\mathrm{a}, \mathrm{c}}$ & $1.43(1.27)^{\mathrm{c}}$ & $1.33(1.29)^{\mathrm{c}}$ \\
Feeling sad & $79(63.2)$ & $1.51(1.41)^{\mathrm{a}, \mathrm{c}}$ & $1.38(1.28)^{\mathrm{c}}$ & $1.30(1.35)^{\mathrm{c}}$ \\
Dry mouth & $77(61.6)$ & $1.46(1.41)^{\mathrm{b}}$ & $1.17(1.14)^{\mathrm{b}}$ & $1.06(1.19)^{\mathrm{a}, \mathrm{b}}$ \\
Difficulty concentrating & $73(58.4)$ & $1.21(1.22)^{\mathrm{c}}$ & $1.06(1.09)^{\mathrm{c}}$ & $0.95(1.14)^{\mathrm{c}}$ \\
Change in the way food tastes & $69(55.2)$ & $1.38(1.46)^{\mathrm{b}}$ & $1.14(1.27)^{\mathrm{b}}$ & $1.03(1.27)^{\mathrm{b}}$ \\
Nausea & $64(51.2)$ & $1.07(1.25)^{\mathrm{b}}$ & $0.97(1.17)^{\mathrm{b}}$ & $0.84(1.12)^{\mathrm{b}}$ \\
Lack of appetite & $60(48.0)$ & $1.09(1.32)^{\mathrm{b}}$ & $0.98(1.18)^{\mathrm{b}}$ & $0.86(1.22)^{\mathrm{a}, \mathrm{b}}$ \\
Dizziness & $51(40.8)$ & $0.90(1.23)^{\mathrm{b}}$ & $0.83(1.14)^{\mathrm{b}}$ & $0.73(1.16)^{\mathrm{b}}$ \\
Feeling bloated & $49(39.2)$ & $0.91(1.33)^{\mathrm{b}}$ & $0.86(1.23)^{\mathrm{b}}$ & $0.80(1.23)^{\mathrm{b}}$ \\
Weight loss & $49(39.2)$ & $0.81(1.21)^{\mathrm{b}}$ & $0.71(1.07)^{\mathrm{b}}$ & $0.48(0.91)^{\mathrm{b}}$ \\
Constipation & $45(36.0)$ & $0.78(1.19)^{\mathrm{b}}$ & $0.77(1.20)^{\mathrm{b}}$ & $1.28(1.46)^{\mathrm{a}, \mathrm{b}}$ \\
Vomiting & $34(27.2)$ & $0.50(0.93)^{\mathrm{b}}$ & $0.47(0.85)^{\mathrm{b}}$ & $0.38(0.80)^{\mathrm{b}}$ \\
\hline
\end{tabular}

${ }^{a}$ Denoted for variables included in the general distress index subscale (GDI)

${ }^{\mathrm{b}}$ Denoted for variables included in the physical symptom subscale

${ }^{\mathrm{c}}$ Denoted for variables included in the psychological symptom subscale
$0.01)$ and higher GDI scores $(1.68 \pm 1.01$ vs. $1.25 \pm 0.84$, respectively; $p<0.05$ ). No other associations were found between socio-demographic (such as age, gender, and family status) or clinical characteristics (such as type of cancer and treatment protocol) and MSAS-Heb scale scores.

The PCC score was negatively correlated with each of the symptom scales. Namely, the GDI, physical symptoms, and psychological symptoms; $r=-.372, p<0.001 ; r=-.317, p<$ $0.001 ; r=-.369, p<0.001$, respectively.

Table 3 shows a series of hierarchical linear regression models for predicting the severity of the GDI, physical symptoms, and psychological symptoms. Only variables that demonstrated no co-linearity were entered into the model. As 'gender' was found to be significantly associated with 'family status' $\left(\chi^{2}=6.83 ; p=0.01\right)$, 'religion' $\left(\chi^{2}=8.09 ; p=\right.$ $0.006)$, and 'being accompanied for treatments' $\left(\chi^{2}=9.28\right.$; $p=0.004$ ), only 'gender' was entered into the regression models.

As shown in Table 3, perceived PCC was found to be associated with each of the symptom scales, beyond sociodemographic and clinical characteristics, in the model (GDI- $\beta=-.351, p<0.001$; physical symptoms $-\beta=$ $-.311, p<0.001$; psychological symptoms $-\beta=-.336 ; p<$ 0.001 ). Furthermore, perceived PCC contributed $11.3 \%$ to explaining the variance of the GDI, and the overall model with the socio-demographic and clinical variables explained $16.8 \%$ of the variance of the GDI. The perceived PCC also contributed $8.9 \%$ to explaining the variance of physical symptoms and $10.3 \%$ to explaining the variance of psychological symptoms. Notably, in the GDI and physical symptoms models, perceived PCC contributed more than a half of the explained variance.

\section{Discussion}

This study's results demonstrate an association between PCC, as perceived by cancer patients undergoing active anti-cancer treatment, and patients' physical, psychological, and global distress-related symptoms. More specifically, the more the participants perceived their treatment approach as patient centered, the lower their global distress and the severity, frequency, or distress level of their physical and psychological symptoms. These findings are in line with previous studies showing that reaching common ground with the primary care physician is associated with improved patient recovery from discomfort and concerns, enhanced emotional health, and decreased diagnostic tests and referrals [41]. Interventions based on information provision, counseling, and emotional support, as well as on symptom management, have also been shown to lead to less patient distress about their symptoms and a higher global health status [36]. However, this study is the first to our knowledge [22] to investigate a large array of symptoms and 
Table 3 Hierarchical linear regression models of for the prediction of symptoms scores

\begin{tabular}{|c|c|c|c|c|c|c|}
\hline & \multicolumn{3}{|c|}{ Model 1} & \multicolumn{3}{|c|}{ Model 2} \\
\hline & $B$ & SE & $\beta$ & $B$ & SE & $\beta$ \\
\hline \multicolumn{7}{|l|}{ Global Distress Index } \\
\hline Gender & -.259 & .165 & -.141 & -.111 & .160 & -.061 \\
\hline Perceived economic status & .468 & .202 & $.206^{*}$ & .351 & .193 & .155 \\
\hline Type of treatment (neo-adjuvant vs. others) & .011 & .158 & -.006 & -.100 & 151 & -.057 \\
\hline Perceived PCC & & & & -.391 & .097 & $-.351 * * *$ \\
\hline$R^{2}$ & & 0.055 & & & .168 & \\
\hline$F$ change for $R^{2}$ & & 2.364 & & & $16.283 * * *$ & \\
\hline$\Delta R^{2}$ & & 0.055 & & & .113 & \\
\hline \multicolumn{7}{|l|}{ Physical symptoms } \\
\hline Gender & -.233 & .134 & -.158 & -.128 & .132 & -.087 \\
\hline Perceived economic status & .190 & .164 & .104 & .106 & .159 & .058 \\
\hline Type of treatment (neo-adjuvant vs. others) & -.093 & .128 & -.065 & -.172 & .125 & -.121 \\
\hline Perceived PCC & & & & -.279 & .080 & $-.311 * * *$ \\
\hline$R^{2}$ & & .039 & & & .128 & \\
\hline$F$ change for $R^{2}$ & & 1.657 & & & $12.190 * * *$ & \\
\hline$\Delta R^{2}$ & & .039 & & & .089 & \\
\hline \multicolumn{7}{|l|}{ Psychological symptoms } \\
\hline Gender & -.320 & .1856 & -.152 & -.158 & .179 & -.075 \\
\hline Perceived economic status & .806 & .226 & $.308 * * *$ & .677 & .216 & $.259 * * *$ \\
\hline Type of treatment (neo-adjuvant vs. others) & -.035 & .177 & -.017 & -.158 & .170 & -.078 \\
\hline Perceived PCC & & & & -.431 & .109 & $-.336 * * *$ \\
\hline$R^{2}$ & & .108 & & & .211 & \\
\hline$F$ change for $R^{2}$ & & $4.898 * *$ & & & $15.696^{* * *}$ & \\
\hline$\Delta R^{2}$ & & .108 & & & .103 & \\
\hline
\end{tabular}

$P C C$ patient-centered care

$* p<0.05 ; * * P<0.01 ; * * * P<0.001$

its association to PCC among cancer patients in a specific, yet crucial phase of their cancer trajectory.

To further explore the contribution of perceived PCC to the experience of symptoms, a series of hierarchical regression models were performed. Our models demonstrated an additive contribution for perceived PCC, beyond socio-demographic, and clinical variables, in explaining the variance of the physical and psychological symptoms, as well as global distress. As perceived economic status was associated with symptom experience, this variable was included in the models. Nonetheless, our results showed that perceived PCC was found to be the only significant variable to explain the variance of the global distress and physical symptoms. When considering the psychological symptoms, perceived PCC explained the variance similarly to perceived economic status. This finding supports a recent report of a negative association between financial strain and quality of life, pain and depression, and overall wellbeing in a large sample of newly diagnosed lung and colorectal cancer patients, even after adjusting for other socio-demographic variables, such as race and ethnicity [42].
Our study's results show that married patients and those who came to their treatment with a companion perceived relatively higher levels of PCC. These findings are supported by previous studies that highlight the key role of informal caregivers in providing physical and emotional support, and assistance in care coordination $[13,14]$. Our findings additionally showed that the lowest mean score of the perceived PCC subscales was obtained for Responding to Emotion. These results strengthen the important role of PCC delivery for single patients without informal caregivers support.

Our findings highlight vulnerable cancer patient groups who may especially profit from higher levels of PCC, namely, cancer patients who are single and those who are in lower socioeconomic situations. For these groups of patients, the PCC approach has the potential to restrict, remove and overcome barriers to achieve a better quality of care $[2,10,11,43]$. The current study also adds to the literature in showing the needs and preferences of cancer patients undergoing active treatment at all stages of disease, especially for receiving medical information and emotional support $[34,36]$. We have provided empirical evidence showing the 
importance of implementing a PCC approach within diverse oncology settings and focused on the way patients perceive their cancer care. In contrast to most previous studies in this field that have been based on planned interventions specifically developed for the period of the study performance, the current study's results are based on observations retrieved from patients' 'real life' experiences while receiving their anti-cancer treatment in an outpatient cancer center. Furthermore, as cancer patients manage several intense symptoms concomitantly [23-25], this study stresses the importance of the perceived PCC as a nonpharmaceutical approach to alleviate patients' physical and psychological symptoms.

This study has several limitations. The study was conducted as a cross-sectional design in a relatively small peripheral cancer center and included a relatively small patient sample. This may prevent the generalizability of the findings to other patients, treatment settings and different disease phases. Additionally, the cross-sectional design of this study does not allow causality inferences. Moreover, the focus in the current study on how the symptoms experienced associate with cancer patients' perceived PCC, prevents the ability to differentiate between treatment, comorbidities and cancerrelated symptoms. A larger cohort study using a longitudinal prospective design and comprising cancer patients of diverse socioeconomic groups and undergoing more comprehensive anti-cancer treatments, such as chemo-, radiation, immuno-, and targeted therapy, is needed to validate our findings.

Nevertheless, these study's findings demonstrate strong associations between perceived PCC and a large array of physical, psychological, and global distress symptoms, together with a noted contribution of economic status to the patients' psychological well-being. While empirical studies on specific PCC frameworks and their impact on specific healthcare outcomes are limited [44], this study contributes empirical findings associated with perceived PCC and the symptom burden in cancer patients undergoing active anti-cancer treatment. Moreover, while patients' economic status and other background factors are not easily amenable to change, oncology care providers can be encouraged to adopt and implement the PCC approach in their routine work and in their ongoing endeavors to alleviate patients' symptoms and suffering, especially for vulnerable groups of cancer patients. In a time of interpersonal distancing as a result of the COVID-19 outbreak, treatment based on the PCC approach is particularly important and ways must be found to implement it even in these special circumstances.

Acknowledgements We are deeply grateful to the patients for their participation and time in the study.

Code availability Not relevant.

Author contribution Inna Tsvitman: This study is based on Inna Tsvitman's master's thesis. Inna was responsible for developing the research question and collecting, managing, and analyzing the data, as well as writing the manuscript draft.

Orit Cohen Castel: Dr. Cohen Castel supervised the thesis project and contributed to the study design and conceptualization, data analysis, and writing of the manuscript.

Efrat Dagan: Prof. Dagan supervised the thesis project and contributed to the study design and conceptualization, data analysis, and writing of the manuscript.

Data availability All the study material is kept by the researchers as is customary.

\section{Declarations}

Ethical approval The study was approved by the Emek Medical Center's Helsinki committee (\#EMC-18-0021) and the University of Haifa's ethical committee (\#149/18).

Consent to participate All patients received an explanation of the research aims and procedures involved, and provided their signed informed consent.

Consent for publication All the authors read and agreed on the final version of the manuscript.

Conflicts of interest The authors declare no competing interests.

\section{References}

1. Hobbs JL (2009) A Dimensional analysis of patient-centered care. Nurs Res 58:52-62. https://doi.org/10.1097/NNR. 0b013e31818c3e79

2. Epstein RM, Fiscella K, Lesser CS, Stange KC (2010) Analysis \& commentary: why the nation needs a policy push on patientcentered health care. Health Aff 29:1489-1495

3. Epstein RM, Street RL (2011) The values and value of patientcentered care. Ann Fam Med 9:100-103

4. Balogh EP, Ganz PA, Murphy SB, Nass SJ, Ferrell BR, Stovall E (2011) Patient-centered cancer treatment planning: improving the quality of oncology care. Summary of an Institute of Medicine Workshop. Oncologist 16:1800-1805. https://doi.org/10.1634/ theoncologist.2011-0252

5. Wolfe A (2001) Institute of Medicine Report: Crossing the Quality Chasm: A New Health Care System for the 21st Century. Policy Polit Nurs Pract 2:233-235. https://doi.org/10.1177/ 152715440100200312

6. Rogers CR (1945) Counseling. Rev Educ Res 15:163. https://doi. org $/ 10.2307 / 1168689$

7. Stewart M, Brown JB, Hammerton J, Donner A, Gavin A, Holliday RL, Whelan T, Leslie K, Cohen I, Weston W, Freeman T (2007) Improving communication between doctors and breast cancer patients. Ann Fam Med 5:387-394

8. WHO | Innovative Care for Chronic Conditions: Building Blocks for Action. https://www.who.int/chp/knowledge/publications/ icccreport/en/. Accessed 16 May 2020

9. Abrahams E, Foti M, Kean MA (2015) Accelerating the delivery of patient-centered, high-quality cancer care. Clin Cancer Res 21: 2263-2267. https://doi.org/10.1158/1078-0432.CCR-15-0827

10. Doubova SV, Martinez-Vega IP, Infante-Castañeda C, ArandaFlores CE, Knaul FM, Pérez-Cuevas R (2020) Social inequalities in supportive care needs and quality of patient-centered care of 
cancer patients in Mexico. Support Care Cancer 29:1355-1367. https://doi.org/10.1007/s00520-020-05615-6

11. Robertson-Jones TA, Tissue MM, Connolly M, Gallups SF, Bender CM, Rosenzweig MQ (2019) Exploring racial differences in patient centeredness of care (PCC) during breast cancer (BC) chemotherapy clinical visits. J Racial Ethn Health Disparities 6:94-100. https:// doi.org/10.1007/s40615-018-0503-0

12. Bertakis KD, Azari R (2011) Patient-centered care is associated with decreased health care utilization. J Am Board Fam Med 24: 229-239

13. Litzelman K, Kent EE, Mollica M, Rowland JH (2016) How does caregiver well-being relate to perceived quality of care in patients with cancer? Exploring associations and pathways. J Clin Oncol 34: 3554-3561. https://doi.org/10.1200/JCO.2016.67.3434

14. Ockerby C, Livingston P, O'Connell B, Gaskin CJ (2013) The role of informal caregivers during cancer patients' recovery from chemotherapy. Scand J Caring Sci 27:147-155. https://doi.org/10. 1111/j.1471-6712.2012.01015.x

15. Radwin LE (2003) Cancer patients' demographic characteristics and ratings of patient-centered nursing care. J Nurs Scholarsh 35: 365-370. https://doi.org/10.1111/j.1547-5069.2003.00365.x

16. Van Ryn M, Phelan SM, Arora NK et al (2014) Patient-reported quality of supportive care among patients with colorectal cancer in the veterans affairs health care system. J Clin Oncol 32:809-815

17. Tirodkar MA, Acciavatti N, Roth LM, Stovall E, Nasso SF, Sprandio J, Tofani S, Lowry M, Friedberg MW, Smith-McLallen A, Chanin J, Scholle SH (2015) Lessons from early implementation of a patient-centered care model in oncology. J Oncol Pract 11: 456-461. https://doi.org/10.1200/jop.2015.006072

18. Epstein RM (2006) Making communication research matter: what do patients notice, what do patients want, and what do patients need? In: Patient Education and Counseling. Elsevier, pp 272-278

19. Fashoyin-Aje LA, Martinez KA, Dy SM (2012) New patientcentered care standards from the commission on cancer: opportunities and challenges. J Support Oncol 10:107-111. https://doi.org/ 10.1016/j.suponc.2011.12.002

20. Mead N, Bower P (2000) Patient-centredness: a conceptual framework and review of the empirical literature. Soc Sci Med 51:10871110. https://doi.org/10.1016/S0277-9536(00)00098-8

21. Fradgley EA, Paul CL, Bryant J (2015) A systematic review of barriers to optimal outpatient specialist services for individuals with prevalent chronic diseases: What are the unique and common barriers experienced by patients in high income countries? Int. J. Equity Health 14

22. Nakaguchi T, Okuyama T, Uchida M, Ito Y, Komatsu H, Wada M, Akechi T (2013) Oncology nurses' recognition of supportive care needs and symptoms of their patients undergoing chemotherapy. Jpn J Clin Oncol 43:369-376. https://doi.org/10.1093/jjco/hyt003

23. Reilly CM, Bruner DW, Mitchell SA, Minasian LM, Basch E, Dueck AC, Cella D, Reeve BB (2013) A literature synthesis of symptom prevalence and severity in persons receiving active cancer treatment. Support Care Cancer 21:1525-1550. https://doi.org/10. 1007/s00520-012-1688-0

24. Esther Kim JE, Dodd MJ, Aouizerat BE, Jahan T, Miaskowski C (2009) A review of the prevalence and impact of multiple symptoms in oncology patients. J Pain Symptom Manag 37:715-736

25. Kwekkeboom KL (2016) Cancer symptom cluster management. Semin Oncol Nurs 32:373-382

26. Hughes M, De La Garza R (2020) 342 self-reported sexual problems predicts higher levels of distress, fatigue and insomnia in patients with cancer. J Sex Med 17:S88-S89. https://doi.org/10.1016/ j.jsxm.2019.11.162

27. Kinnaird W, Stewart-Lord A (2020) A qualitative study exploring men's experience of sexual dysfunction as a result of radiotherapy and androgen deprivation therapy to treat prostate cancer. Radiography 26:S16. https://doi.org/10.1016/j.radi.2019.11.039
28. Davis LE, Bubis LD, Mahar AL, Li Q, Sussman J, Moody L, Barbera L, Holloway CMB, Coburn NG (2018) Patient-reported symptoms after breast cancer diagnosis and treatment: a retrospective cohort study. Eur J Cancer 101:1-11. https://doi.org/10.1016/j. ejca.2018.06.006

29. Thong MSY, Doege D, Koch-Gallenkamp L, Bertram H, Eberle A, Holleczek B, Waldeyer-Sauerland M, Waldmann A, Zeissig SR, Brenner H, Arndt V (2019) Age at diagnosis and sex are associated with long-term deficits in disease-specific health-related quality of life of survivors of colon and rectal cancer: a population-based study. Dis Colon Rectum 62:1294-1304. https://doi.org/10.1097/ DCR.0000000000001489

30. Braamse AMJ, Van Turenhout ST, Terhaar Sive Droste JS et al (2016) Factors associated with anxiety and depressive symptoms in colorectal cancer survivors. Eur J Gastroenterol Hepatol 28:831835. https://doi.org/10.1097/MEG.0000000000000615

31. Thomas BC, Waller A, Malhi RL, Fung T, Carlson LE, Groff SL, Bultz BD (2014) A longitudinal analysis of symptom clusters in cancer patients and their sociodemographic predictors. J Pain Symptom Manag 47:566-578. https://doi.org/10.1016/j. jpainsymman.2013.04.007

32. Stewart M, Brown JB, Donner A, McWhinney I, Oates J, Weston WW, Jordan J (2000) The impact of patient-centered care on outcomes. J Fam Pract 49:796-804

33. Rathert C, Wyrwich MD, Boren SA (2013) Patient-centered care and outcomes: a systematic review of the literature. Med Care Res Rev 70:351-379. https://doi.org/10.1177/1077558712465774

34. Epstein RM, Duberstein PR, Fenton JJ, Fiscella K, Hoerger M, Tancredi DJ, Xing G, Gramling R, Mohile S, Franks P, Kaesberg P, Plumb S, Cipri CS, Street RL Jr, Shields CG, Back AL, Butow P, Walczak A, Tattersall M, Venuti A, Sullivan P, Robinson M, Hoh B, Lewis L, Kravitz RL (2015) Effect of a patient-centered communication intervention on oncologist-patient communication, quality of life, and health care utilization in advanced cancer the VOICE randomized clinical trial. JAMA Oncol 1:92-100. https:// doi.org/10.1001/jamaoncol.2016.4373

35. Schellinger SE, Anderson EW, Frazer MS, Cain CL (2018) Patient self-defined goals: essentials of person-centered care for serious illness. Am J Hosp Palliat Med 35:159-165. https://doi.org/10. 1177/1049909117699600

36. Tuominen L, Stolt M, Meretoja R, Leino-Kilpi H (2019) Effectiveness of nursing interventions among patients with cancer: an overview of systematic reviews. J Clin Nurs 28:2401-2419

37. Faul F, Erdfelder E, Lang AG, Buchner A (2007) G*Power 3: A flexible statistical power analysis program for the social, behavioral, and biomedical sciences. In: Behavior Research Methods. Psychonomic Society Inc., pp 175-191

38. Portenoy RK, Thaler HT, Kornblith AB, McCarthy Lepore J, Friedlander-Klar H, Kiyasu E, Sobel K, Coyle N, Kemeny N, Norton L, Scher H (1994) The Memorial Symptom Assessment Scale: an instrument for the evaluation of symptom prevalence, characteristics and distress. Eur J Cancer 30:1326-1336. https:// doi.org/10.1016/0959-8049(94)90182-1

39. Pud D (2015) The psychometric properties of the Hebrew version of the Memorial Symptom Assessment scale (MSAS-Heb) in patients with breast cancer. J Pain Symptom Manag 49:790-795. https://doi.org/10.1016/j.jpainsymman.2014.08.016

40. Reeve BB, Thissen DM, Bann CM, Mack N, Treiman K, Sanoff HK, Roach N, Magnus BE, He J, Wagner LK, Moultrie R, Jackson KD, Mann C, McCormack LA (2017) Psychometric evaluation and design of patient-centered communication measures for cancer care settings. Patient Educ Couns 100:1322-1328. https://doi.org/10. 1016/j.pec.2017.02.011

41. Oates J, Weston W, Pract JJ-F (2000) U (2000) The impact of patient-centered care on outcomes. J Fam Pract 49:796-804 
42. Lathan CS, Cronin A, Tucker-Seeley R, Zafar SY, Ayanian JZ, Schrag D (2016) Association of financial strain with symptom burden and quality of life for patients with lung or colorectal cancer. J Clin Oncol 34:1732-1740. https://doi.org/10.1200/JCO.2015.63. 2232

43. Bertakis KD, Azari R (2011) Determinants and outcomes of patient-centered care. Patient Educ Couns 85:46-52. https://doi. org/10.1016/j.pec.2010.08.001
44. Constand MK, MacDermid JC, Dal Bello-Haas V, Law M (2014) Scoping review of patient-centered care approaches in healthcare. BMC Health Serv Res 14:271. https://doi.org/10.1186/1472-6963$14-271$

Publisher's note Springer Nature remains neutral with regard to jurisdictional claims in published maps and institutional affiliations. 